\title{
An episode of cerebrospinal fluid leak syndrome involving a marathon runner
}

\author{
Kazumasa Sudo, ${ }^{1}$ Yasunori Mito, ${ }^{1}$ Yasutaka Tajima, ${ }^{1}$ Akihisa Matsumoto, ${ }^{1}$ Chihoko Miyazaki, ${ }^{2}$ \\ Kunio Tashiro ${ }^{3}$
}

1Department of Neurology, Sapporo City General Hospital, Chuo-Ku, Sapporo, Japan;

2Department of Diagnostic Radiology, Sapporo City General Hospital, Chuo-Ku, Sapporo, Japan;

${ }^{3}$ Department of Neurology, Hokuyukai Neurological Hospital, Nishiku, Sapporo, Japan

Correspondence to Kazumasa Sudo kazumasa.sudo@doc.city.sapporo.jp

\section{DESCRIPTION}

A 57-year-old marathon runner presented with orthostatic dizziness and headache, which appeared just after running a few kilometres and had persisted for 7 days. No other neurological abnormalities were found. On lumbar puncture, the initial pressure was zero. A cranial MRI with gadolinium showed a marked enhancement of the dura mater (figure 1, arrows). MR cisternography and holocord MR myelography revealed a cerebrospinal fluid (CSF) leak at the right C3 and C4 spinal root sleeves (figure 2, arrows). The patient was confined to complete bed rest under the administration of necessary intravenous fluids for 14 days. On the 14th hospital day, orthostatic symptoms had resolved and MR myelography demonstrated the disappearance of the CSF leak (figure 3). He resumed occasional running 6 months later in the absence of any recurrence of the symptoms and a follow-up cranial MRI

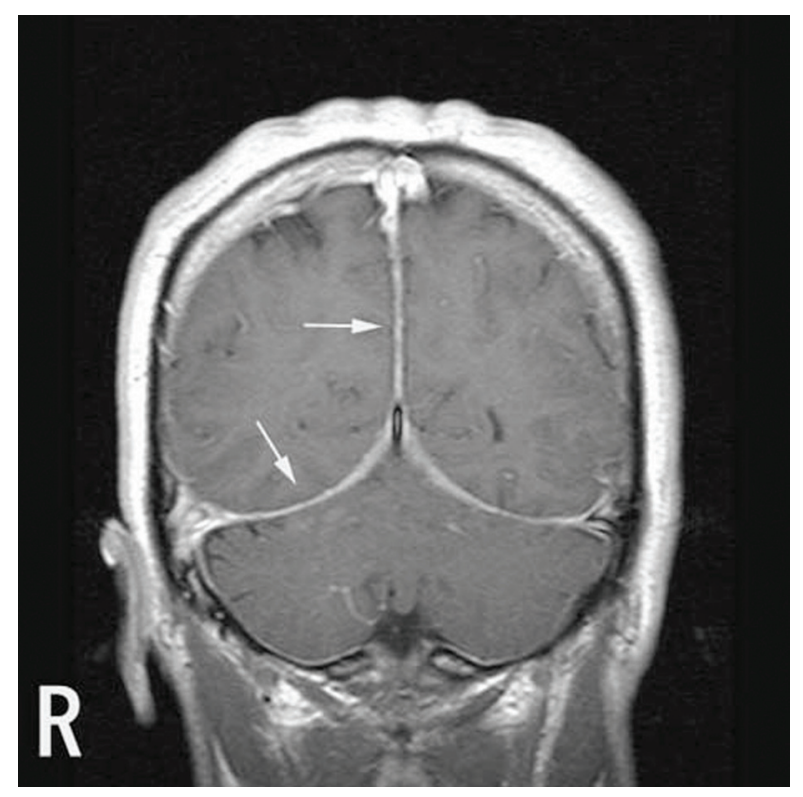

Figure 1 Gadolinium MRI on admission. with gadolinium confirmed the disappearance of dura mater enhancement (figure 4).

CSF leak syndrome is usually caused by various degrees of trauma. ${ }^{1}{ }^{2}$ The strain of running had not been excessive for this individual, but the mode of onset suggested that running must have had some influence on the initial appearance of this disorder. Although blood patching of the dura mater is focused on as a method of treatment for this condition, ${ }^{2}{ }^{3}$ in some cases recovery is seen after a certain number of days of complete bed rest. ${ }^{2}$ If accurate

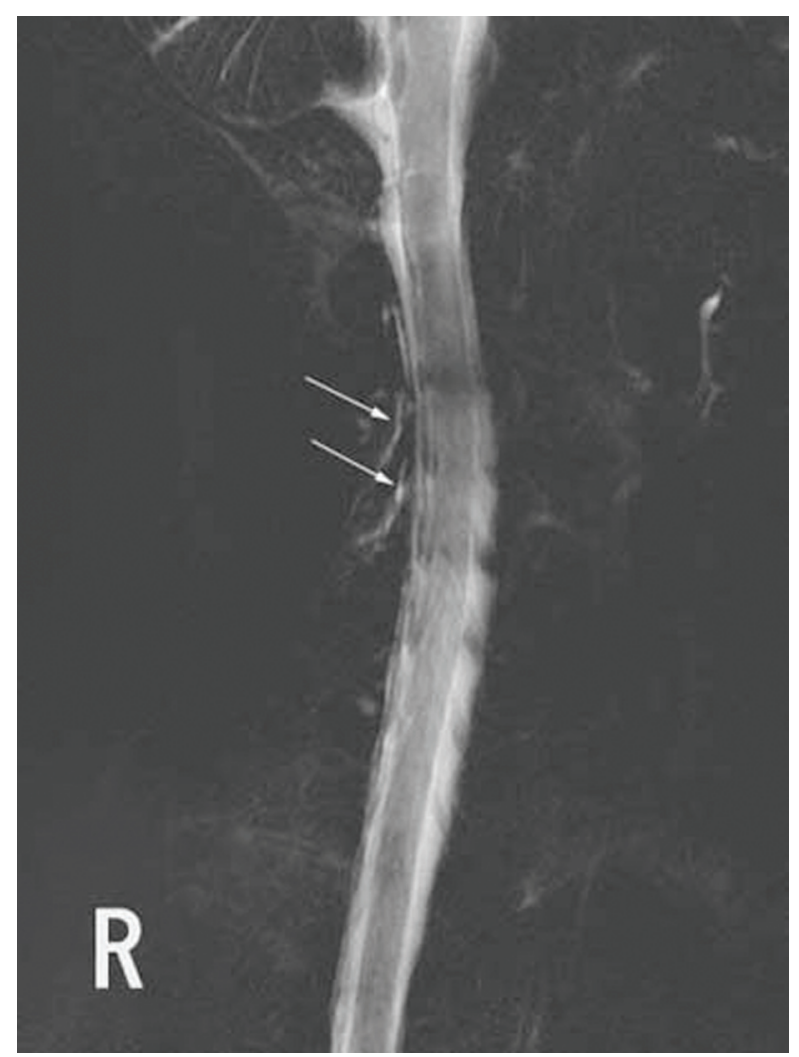

Figure 2 MR myelography (right anterior oblique) on admission. 


\section{BMJ Case Reports}

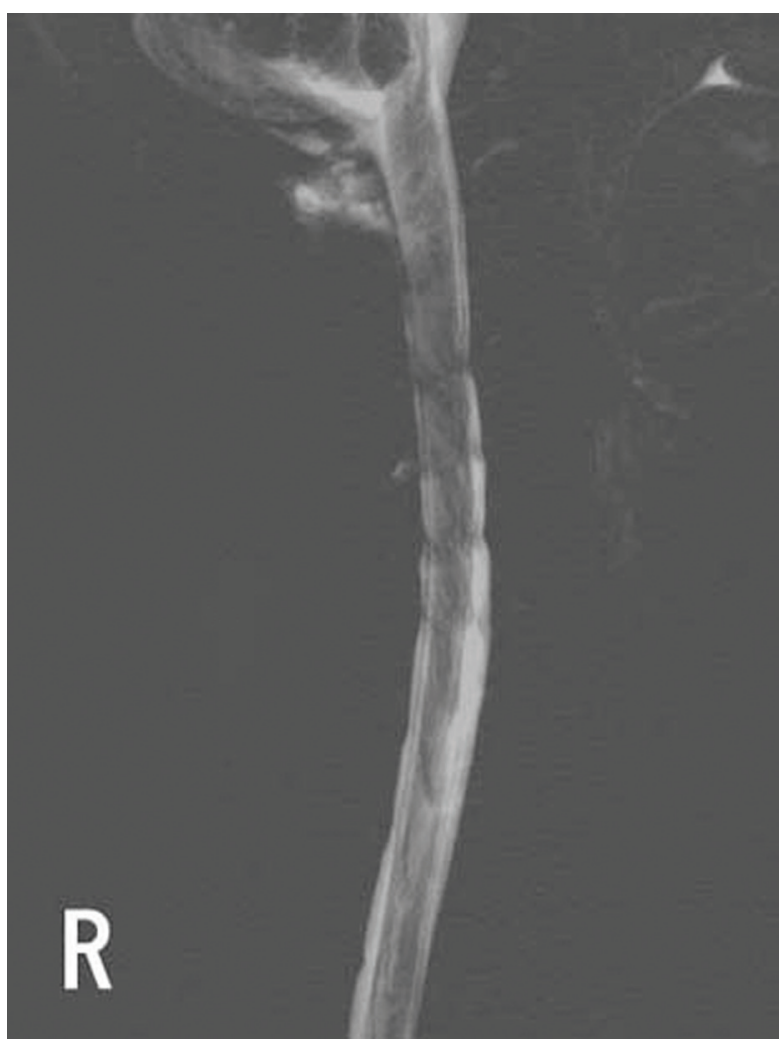

Figure 3 MR myelography (right anterior oblique) before discharge.

and early diagnosis of this syndrome can be made, a more conservative method is sometimes adequate. ${ }^{2}$

Competing interests None.

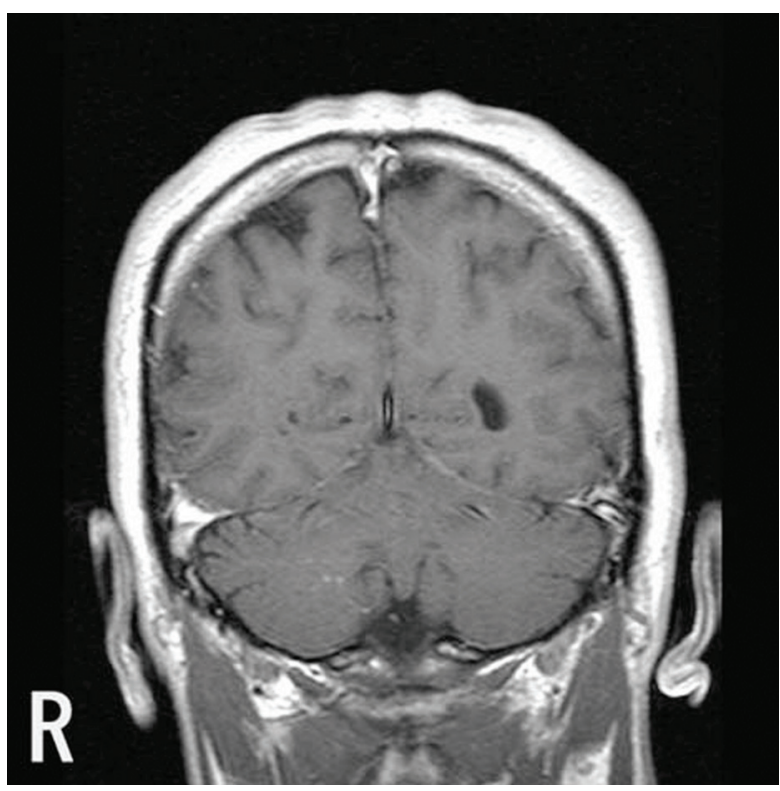

Figure 4 Gadolinium MRI after clinical resolution.

Patient consent Obtained

\section{REFERENCES}

1. Huntoon MA, Watson JC. Intracranial hypotension following motor vehicle accident: an overlooked cause of post-traumatic head and neck pain? Pain Pract 2007; 7:47-52.

2. Schievink WI, Maya MM, Louy C, et al. Diagnostic criteria for spontaneous spinal CSF leaks and intracranial hypotension. AJNR Am J Neuroradiol 2008;29:853-6.

3. Yoo HM, Kim SJ, Choi CG, et al. Detection of CSF leak in spinal CSF leak syndrome using MR myelography: correlation with radioisotope cisternography. AJNR Am J Neuroradiol 2008;29:649-54.

This pdf has been created automatically from the final edited text and images.

Copyright 2011 BMJ Publishing Group. All rights reserved. For permission to reuse any of this content visit

http://group.bmj.com/group/rights-licensing/permissions.

BMJ Case Report Fellows may re-use this article for personal use and teaching without any further permission.

Please cite this article as follows (you will need to access the article online to obtain the date of publication).

Sudo K, Mito Y, Tajima Y, Matsumoto A, Miyazaki C, Tashiro K. An episode of cerebrospinal fluid leak syndrome involving a marathon runner. BMJ Case Reports 2011;10.1136/bcr.12.2010.3571, date of publication

Become a Fellow of BMJ Case Reports today and you can:

- Submit as many cases as you like

- Enjoy fast sympathetic peer review and rapid publication of accepted articles

- Access all the published articles

- Re-use any of the published material for personal use and teaching without further permission

For information on Institutional Fellowships contact consortiasales@bmjgroup.com

Visit casereports.bmj.com for more articles like this and to become a Fellow 